\title{
HEAT STORAGE EFFECT OF THE OPERATIVE TEMPERATURE IN PASSOL LABORATORY
}

\author{
I. CSÁKY*, M. LAKATOS \\ Department of Building Services and Building Engineering, University of Debrecen, 4028 Debrecen, Ótemető u. 2-4, Hungary \\ *E-mail: imrecsaky@eng.unideb.hu
}

In different Comfort Standards, for different building functions the requirements for summer and also for winter period differ. The operative temperature is one of these parameters, which in different Comfort Standards for summer-winter period specifies the building's comfort category.

This paper presents the results of measurement of the operative temperature in PASSOL laboratory with different heat storage and using night ventilation.

Keywords: PASSOL laboratory, operative temperature, thermal mass, torrid day, night ventilation

\section{Introduction}

We spend $80-90 \%$ of our life in indoor environment. Nowadays, in new buildings, more and more glazed surfaces are used which lead to the higher summer heat load. Therefore, the cooling needs are drastically increasing if we do not pay attention to choose windows with appropriate shadings and solar factor [1]. The operative temperature is significantly influenced by the size of the windows and by the buildings time constant. Consequently, transparent surfaces are influencing considerably the evolving thermal comfort in a closed space. Naturally, beside of these thermal comfort also depends on many other factors [2].

Currently, in Hungary, buildings use $40 \%$ of all energy, more than two-thirds are used for heating and cooling. Unfortunately, that energy use is wasteful, because most buildings do not meet today's requirements. $70 \%$ of Hungary's population, approximately 4.3 million homes do not meet the modern functional and thermal technical requirements, and the proportion is similar for public buildings [3].

Already the European Parliament and its Council have a statement about the energy use in households from 2010. This statement includes: "The number of air conditioning systems in European countries has increased in recent years. This causes significant problems during peak periods, increasing electricity costs and destabilizing energy balance in these countries. Priority should be given to strategies that enhance the thermal performance of buildings during the summer period. To this end, priority should be given to measures to prevent overheating, such as providing shielding and the necessary heat capacity of the building structure, as well as further developing and applying passive cooling technologies which improve indoor climatic conditions and the microclimate around the building." [4]

Moreover, the Official Journal of the European Union L 156/77 (15) has an article. "It is important to ensure that measures to improve the energy performance of buildings do not focus only on the building envelope, but include all relevant elements and technical systems in a building, such as passive elements that participate in passive techniques aiming to reduce the energy needs for heating or cooling, the energy use for lighting and ventilation and hence improve thermal and visual comfort." [5]

Open Access statement. This is an open-access article distributed under the terms of the Creative Commons Attribution 4.0 International License (https://creativecommons.org/licenses/by/4.0/), which permits unrestricted use, distribution, and reproduction in any medium, provided the original author and source are credited, a link to the CC License is provided, and changes - if any - are indicated. (SID_1) 
Low energy technologies may reduce cooling energy needs. Natural ventilation is a traditional and cost-effective way for building cooling and ventilation. One of the most obvious processes of cooling is night-time ventilation. We can determine when it is worth to use night-time ventilation with a light and heavy structure for different temperature conditions to minimize the cooling energy consumption [6-8].

When windows and other passive ventilation openings are opened, in the early and late hours of the day, natural ventilation can be exploited to get the hot air out of the building and thereby cool the internal heat storage mass to make the days more comfortable $[9,10]$.

Many articles have shown the relationship between the thermal mass and night-time ventilation. Buildings which have curtain walls are becoming more and more popular, these walls are drastically increasing the excess heat load through the transparent surfaces in the buildings. Therefore, it is worth to consider how to reduce the internal air temperature by night ventilation and how the temperature attenuation will affect [11].

The efficiency of night-time ventilation is influenced by the outside air temperature. At the same time, when designing a large glazed surface, the heat transfer capacity of the glass is much higher than the wall which is surrounding the room. This may have a significant influence on the room's heat loads, in extremely warm weather conditions, greatly influencing the increase of indoor air temperature. During our study we observed that the number of hot days has a significant impact on the use of air conditioning equipment $[12,13]$.

Night-time ventilation is useful if the openings (doors and windows) are correctly placed in building structure, and the large airflow is guaranteed.

The actual rooms can be flushed with great efficiency and cool the heat storage mass. Large air exchange can be created; it is especially useful for the night time to make sure that comfort is not compromised by the optimal condition of the building. It is highly useful when the outside air is much cooler than the inside air, it is easier to use pressure differential and gravity flow [14].

Accordingly, Department of Building Services and Building Engineering, University of Debrecen created a microenvironment by various heat storage (with bricks, without bricks) in the PASSOL laboratory, and night ventilation was also integrated.

\section{PASSOL Laboratory}

In the present article you can read a summarized presentation of the PASSOL laboratory. In the above men-

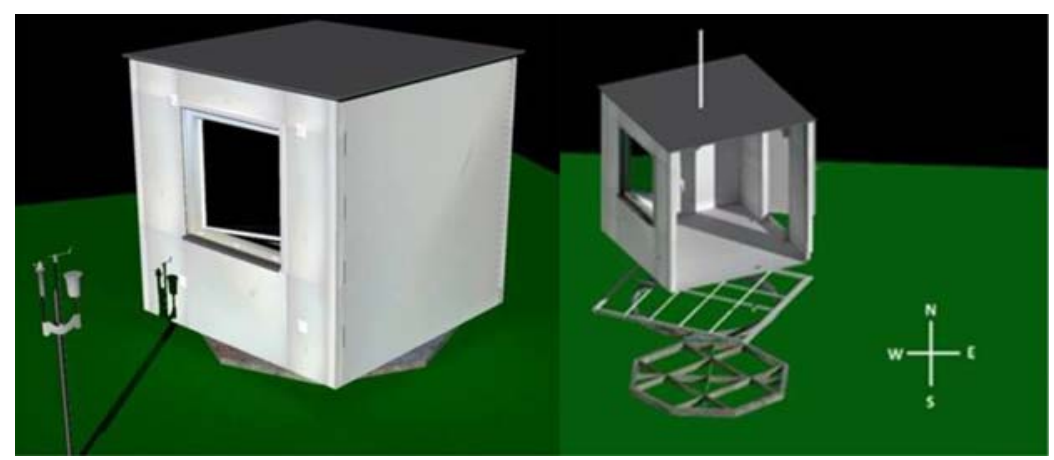

Fig. 1. PASSOL Laboratory

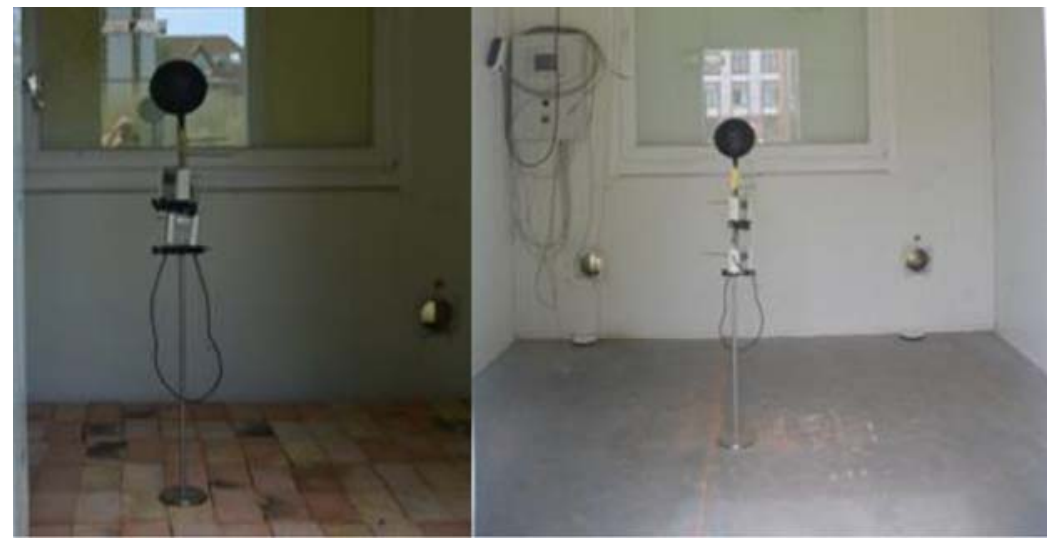

Fig. 2. PASSOL Laboratory with and without heat storage mass 


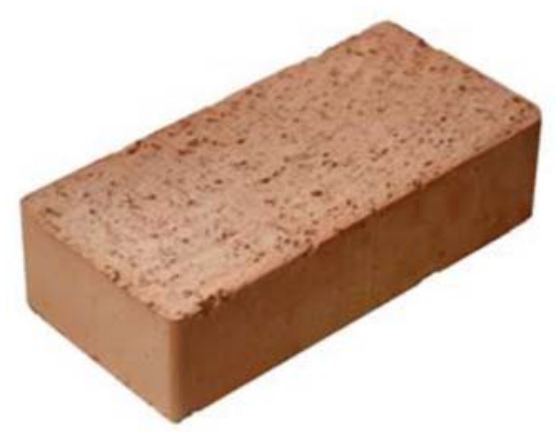

Fig. 3. Common brick

tioned articles you can read a more detailed version of the laboratory description $[15,16]$.

A rotating laboratory, called PASSOL, was set up at the Department of Building Services and Building Engineering, Faculty of Engineering, University of Debrecen, next to the city center. The geographical location of Debrecen is $4731.8^{\prime} \mathrm{N}$ and $2137.8^{\prime} \mathrm{E}$. This special facility was built up for internal temperature fluctuation measurement analysis, especially in summer period. The closed space has the above inner dimensions: $2.6 \times 2.6 \times 2.6 \mathrm{~m}$. The same sandwich panels are built in the flat roof covered with aluminum tables. A special mechanism permits the rotation of the whole laboratory around its own axes.

The laboratory is set up from prefabricated $200 \mathrm{~mm}$ thick sandwich panels, used for refrigeration chambers. The overall heat transfer coefficient is $0.146 \mathrm{~W} / \mathrm{m}^{2} \mathrm{~K}$, with a $40 \mathrm{~kg} / \mathrm{m}^{3}$ polyurethane foam density. In one of the external walls a $150 \times 150 \mathrm{~cm}$ glazed surface was built in at a height of $0.9 \mathrm{~m}$ having $1.4 \mathrm{~W} / \mathrm{m}^{2} \mathrm{~K} \mathrm{U}$ value. There is also a special door built for chambers refrigeration.

During the measurements on the floor of the test room common brick was placed in different layers: one layer of brick which means 136 pieces having

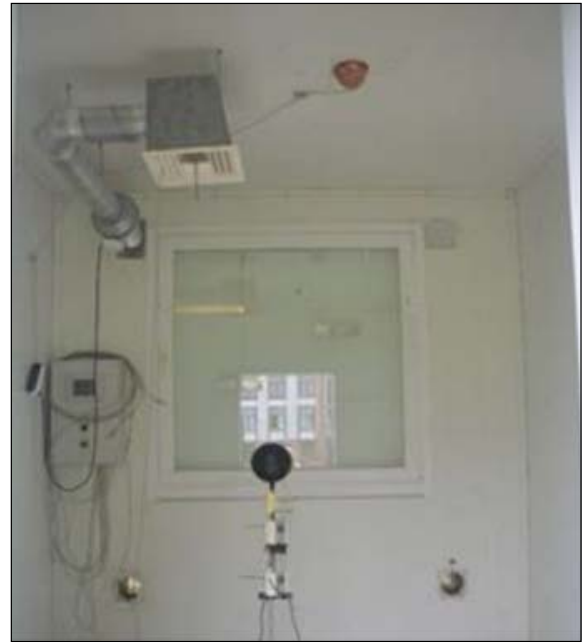

Fig. 4. PASSOL Laboratory with air ventilation system

$340 \mathrm{~kg}$, two rows of bricks which means 272 pieces having $680 \mathrm{~kg}$.

The brick's thermal properties are: $\lambda=0.78$ $[\mathrm{W} / \mathrm{mK}], \rho=1730\left[\mathrm{~kg} / \mathrm{m}^{3}\right], c=880[\mathrm{~J} / \mathrm{kgK}]$, having the following dimension properties $120 \times 64 \times$ $250 \mathrm{~mm}$ and $2.5 \mathrm{~kg}$.

After the heat storage measurement, the PASSOL laboratory was equipped with air ventilation system. The air ventilation system contains: air duct, fan, air diffuser as it is shown in Fig. 4.

Using the air ventilation system, we examined the night ventilation effect of the operative temperature.

Before the experimental series the air tightness measurements were carried out with a Remotec 3300 Blower Door measuring equipment. Initially, a blower door test was conducted to verify the air tightness of the test room. The measurements showed that there is relatively no air change rate between the laboratory and the external environment, even at a pressure difference (indoor versus outdoor) of $\pm 200 \mathrm{~Pa}$.

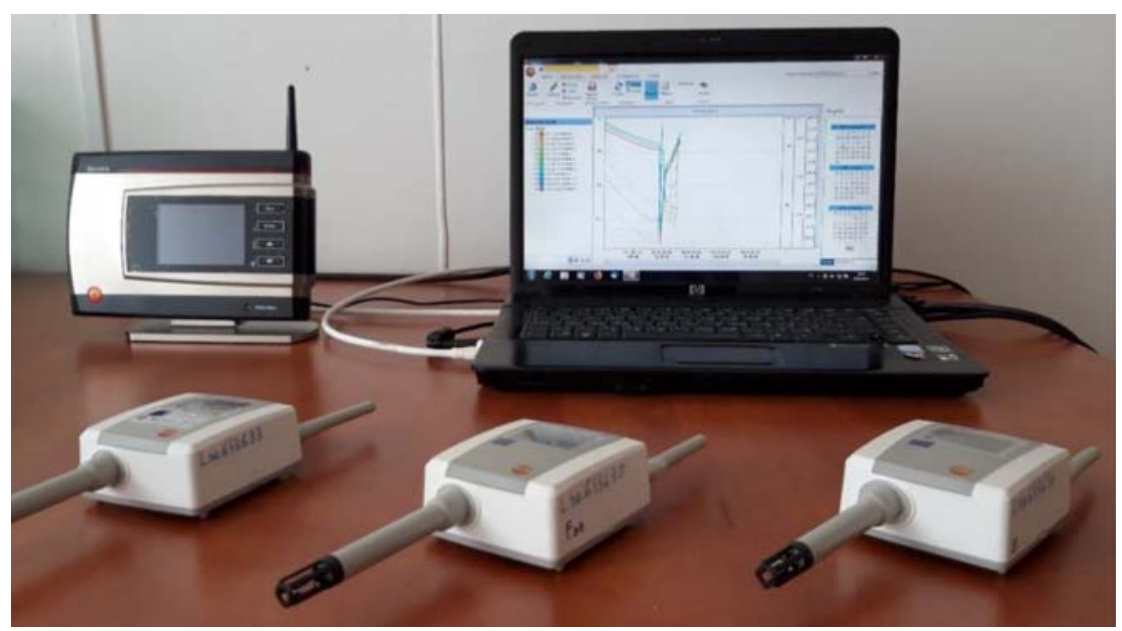

Fig. 5. The Testo Saveris measurement system 


\section{The Testo Saveris measurement system}

During the measurement series in the test room Testo Saveris measurement system was used. This measurement system can also be used for monitoring the building air conditioning.

With the measurement system, ambient or process data for temperature and humidity in sealed rooms and/or during transportation is measured and recorded using probes. These measured values are transmitted by radio to the Saveris base and saved. The data is then called up from a computer by the Saveris base and saved to a database.

The NTC sensor measuring range of the Saveris T2/T2D is from -35 to $+50{ }^{\circ} \mathrm{C}$ and the accuracy is $\pm 0.2{ }^{\circ} \mathrm{C}\left(-25\right.$ to $\left.+70{ }^{\circ} \mathrm{C}\right)[17]$.

\section{Measurement results}

In the PASSOL laboratory we measured the operative temperature in summer, hot and torrid days.

According to the Hungarian Meteorological Service, days that have a maximum temperature:

$$
\begin{array}{ll}
\text { - Summer days } & T_{\max }>25^{\circ} \mathrm{C}, \\
- \text { Hot days } & T_{\max } \geq 30^{\circ} \mathrm{C}, \\
- \text { Torrid days } & T_{\max } \geq 35^{\circ} \mathrm{C}[18] .
\end{array}
$$

The requirements related to the operative temperature in different building types are established in function with the comfort category $[19,20]$.

The operative temperature may be defined as the average of the mean radiant and indoor air temperature [21].

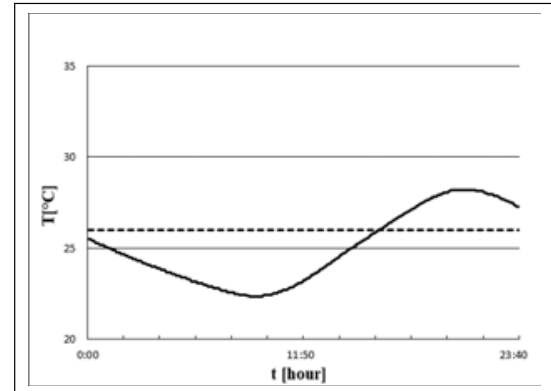

a)

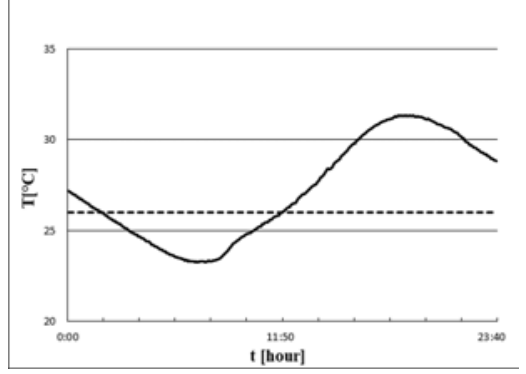

a)

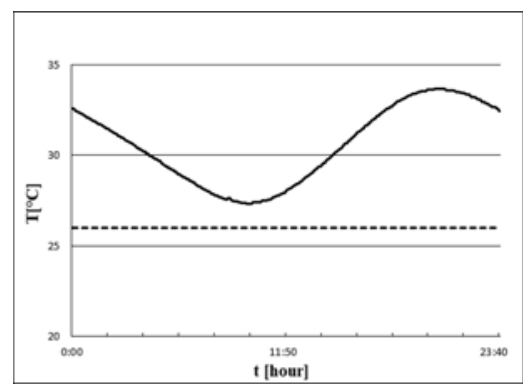

a)

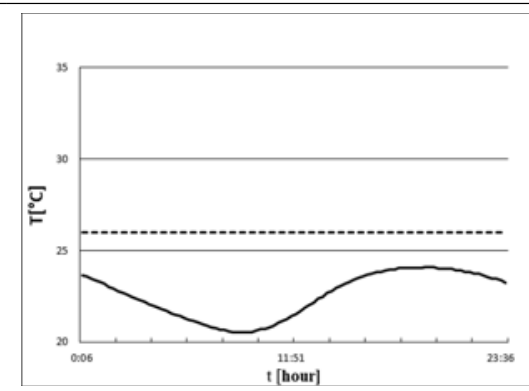

b)

Operative temperature in summer day

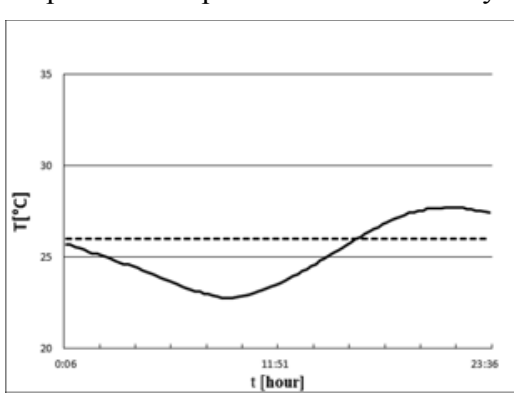

b)

Operative temperature in hot day

b)

Operative temperature in torrid day

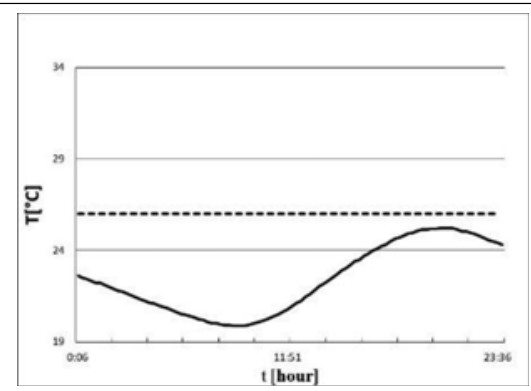

c)

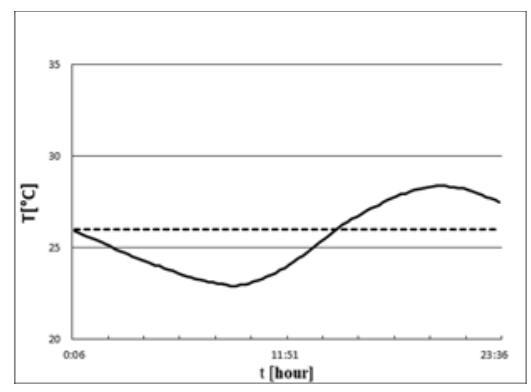

c)

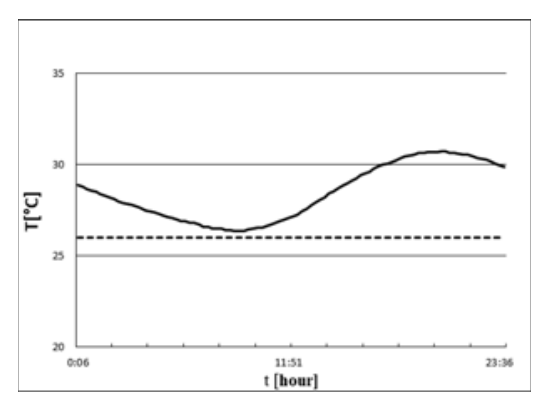

c)

Fig. 6. Measured operative temperature. a) without brick; b) 1 row of brick, containing 136 pieces, having $340 \mathrm{~kg}$, c) 2 rows of bricks, containing 272 pieces, having $680 \mathrm{~kg}$ 


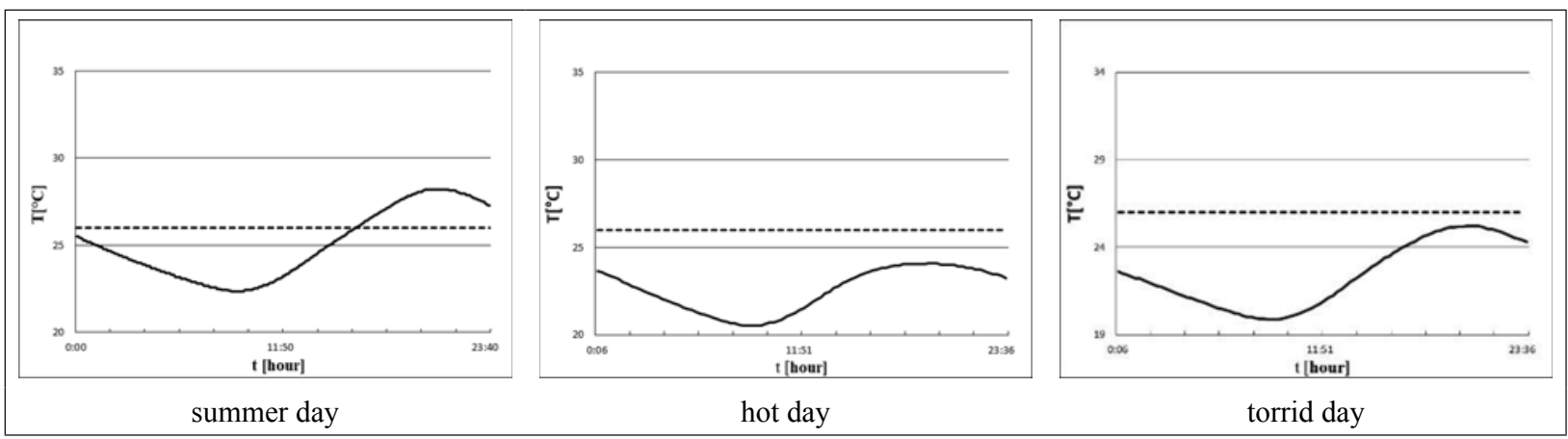

Fig. 7. Measured operative temperature used night ventilation

Due to the fact that in many standards the building types are typified the operative temperature we investigated in different situations are the following:

- without air ventilation system:

- without brick, one row of brick, two rows of brick,

- with air ventilation system

- two rows of brick with night ventilation.

The minimum operative temperature in summer day with two rows of brick is $19.88^{\circ} \mathrm{C}$.

In Fig. 7 we presented the operative temperature in summer period where we used the night ventilation, 4 hour and $3\left[\mathrm{~h}^{-1}\right]$ air change rate.

\section{Calculations of the operative temperature}

The PASSOL laboratory's operative temperature was calculated first of all using the European ISO 13790 (2008) Standard methodology, secondly the input global solar radiation and also the hourly temperatures in summer, hot and torrid days (provided by Debrecen's Agro-Meteorological Observatory). With Kipp and Zomen CMP-11 equipment ( $\pm 1 \%$ accuracy) was measured the global radiation and Pt 100-1/10 temperature sensor ( $\pm 1 \%$ accuracy).

The calculation method uses the RC network of the heat flows, as shown in Fig. 8 [22].

Heat transfer by ventilation, $H_{v e}$, is directly connected both to the air temperature node, $\theta_{\text {air }}$ and to

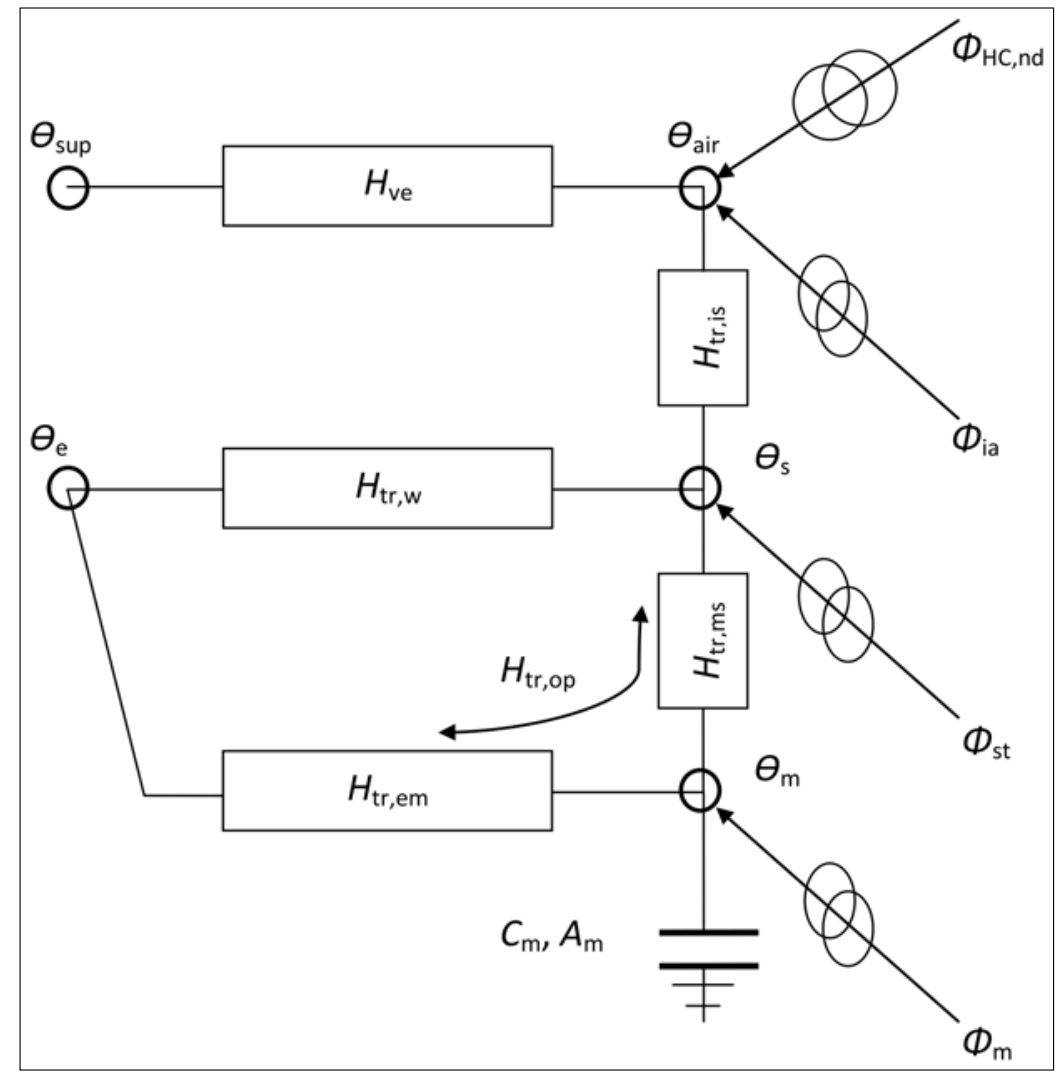

Fig. 8. RC network heat flows [22] 
the node representing the supply temperature, $\theta_{\text {sup }}$. Heat transfer by transmission is split into the window segment, $H_{t r, w}$, which is assumed to have zero thermal mass, and the remainder, $H_{t r}$ op, which contains the thermal mass is split into two parts, $H_{t r, e m}$ and $H_{t r}$. $m_{s}$. Solar and internal gains are distributed over the air node, $\theta_{\text {air }}$, the central node $\theta_{s}$ (a mix of $\theta_{\text {air }}$ and mean radiant temperature) and the node representing the mass of the building zone, $\theta_{m}$. The thermal mass is represented by a single thermal capacity, $C_{m}$, that is located between $H_{t r, m s}$ and $H_{t r, e m}$. A coupling conductance is defined between the internal air node and the central node. The heat flow rate given by internal heat sources, $\Phi_{\text {int }}$, and solar heat sources, $\Phi_{\text {sol }}$, is split among the three nodes [22]. The internal heat capacity of the building zone, $C_{m},[\mathrm{~J} / \mathrm{K}]$, was calculated for a maximum thickness of $10 \mathrm{~cm}$.

The solution model is based on a Cranck-Nicholson scheme, considering a time step of one hour.

The air temperature is given by Eq. (1) [22]:

$$
\theta_{\mathrm{air}}=\frac{H_{t r, i s} \theta_{s}+H_{v e} \theta_{\mathrm{sup}}+\Phi_{i a}+\Phi_{H C, n d}}{H_{t r, i s}+H_{v e}},
$$

where $H_{t r \text {, is }}$ is the transmission heat transfer coefficient, $[\mathrm{W} / \mathrm{K}] ; H_{v e}$ is the ventilation heat transfer coefficient, $[\mathrm{W} / \mathrm{K}]$; and $\Phi_{H C, n d}-$ is the cooling need of the building, [W].

$$
\Phi_{i a}=0.5 \Phi_{\mathrm{int}},
$$

where $\Phi_{\text {int }}$ is the heat flow rate from internal heat sources [W].

The node temperature, $\theta_{s}$, is given by Eq. (3) [22]:

$\theta_{s}=$

$\frac{H_{t r, m s} \theta_{m}+\Phi_{s t}+H_{t r, w} \theta_{e}+H_{t r, 1}\left(\theta_{\text {sup }}+\frac{\Phi_{i a}+\Phi_{H c, n d}}{H_{v e}}\right)}{H_{t r, m s}+H_{t r, w}+H_{t r, 1}}$,

where $\theta_{e}$ is the temperature of the external environment $\left[{ }^{\circ} \mathrm{C}\right]$.

$$
\begin{gathered}
H_{t r, 1}=\left[1 / H_{v e}+1 / H_{t r, i s}\right]^{-1,} \\
\Phi_{s t}=\left(1-\frac{A_{m}}{A_{t}}-\frac{H_{t r, w}}{9.1 A_{t}}\right)\left(0.5 \Phi_{\mathrm{int}}+\Phi_{\mathrm{sol}}\right),
\end{gathered}
$$

where $A_{t}$ is the area of all surfaces facing the building zone $\left[\mathrm{m}^{2}\right]$.

The coupling conductance between nodes $m$ and $s,[\mathrm{~W} / \mathrm{K}]$, is given by Eq. (6) [22]:

$$
H_{t r, m s}=h_{m s}+A_{m} \text {, }
$$

where $h_{m s}$ is the heat transfer coefficient between nodes $m$ and $s\left[\mathrm{~W} / \mathrm{m}^{2} \mathrm{~K}\right]$ and $A_{m}$ is the effective mass area $\left[\mathrm{m}^{2}\right]$.

The operative temperature is obtained using Eq. (7) [22]:

$$
\theta_{\text {op }}=0.3 \theta_{\text {air }}+0.7 \theta_{s}
$$

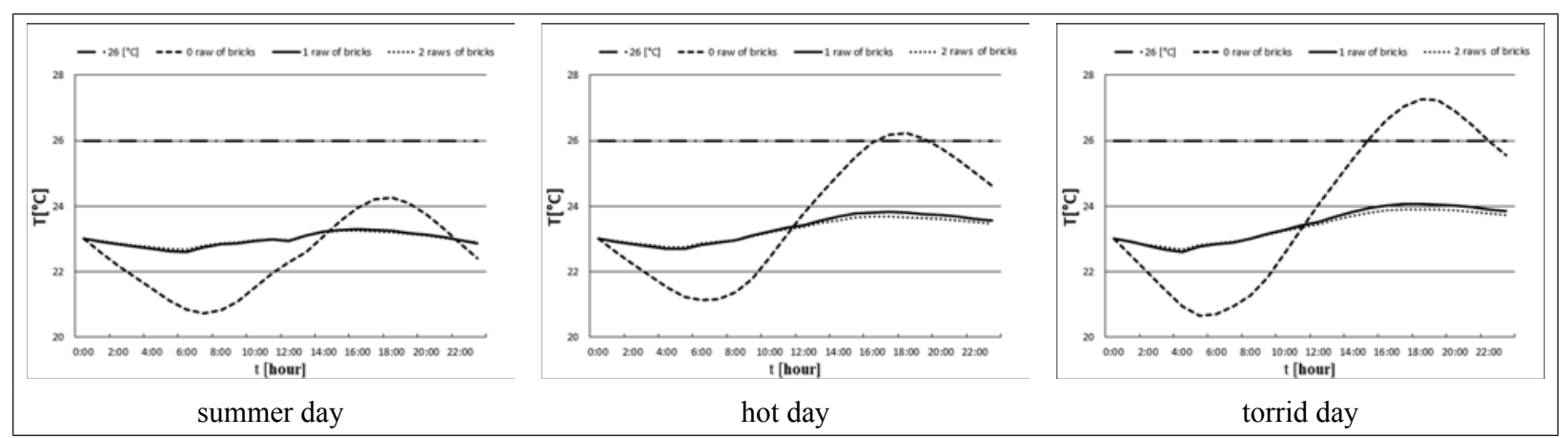

Fig. 9. Calculated operative temperature

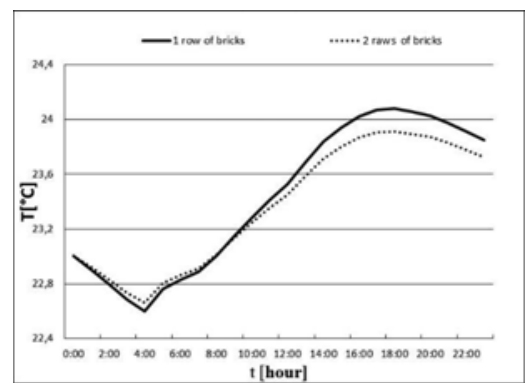

Fig. 10. Calculated operative temperature with 1 and 2 rows of bricks
The calculated operative temperature values in the PASSOL laboratory considered for different heat storage mass in summer, hot and torrid days are shown in Fig. 9.

In summer, hot and torrid days the maximum external temperature is $28.2{ }^{\circ} \mathrm{C}, 31.9^{\circ} \mathrm{C}, 35.1^{\circ} \mathrm{C}$.

The maximum difference between the calculated operative temperature with 1 row of brick and 2 rows of brick is $0.165^{\circ} \mathrm{C}$, which is presented in Fig. 10. 


\section{Conclusion}

The measurement equipment with high accuracy permits an exact measurement of the operative temperature in the PASSOL laboratory.

The PASSOL laboratory permits the measurement of operative air temperatures for different heat storage mass and night ventilation in summer period (summer, hot, torrid days).

The differences between the external average temperature and measured average operative temperature in different case studies are:

In summer days without brick the difference is $1.6{ }^{\circ} \mathrm{C}$, with 1 row of brick the difference is $2.25^{\circ} \mathrm{C}$ and with 2 rows of bricks is $2.19^{\circ} \mathrm{C}$.

In hot days without brick the difference is 1.89 ${ }^{\circ} \mathrm{C}$, with 1 row of brick the difference is $0.22{ }^{\circ} \mathrm{C}$ and with 2 rows of bricks is $2.32{ }^{\circ} \mathrm{C}$.

In torrid days without brick the difference is $2.68{ }^{\circ} \mathrm{C}$, in case of 1 row of brick there are no collected data and with 2 rows of bricks it is $0.54{ }^{\circ} \mathrm{C}$.

Using the night ventilation in PASSOL laboratory in summer days with 2 rows of bricks the difference is $0.84{ }^{\circ} \mathrm{C}$, in hot days $0.66{ }^{\circ} \mathrm{C}$, in torrid days $0.74{ }^{\circ} \mathrm{C}$.

In this article the results of the measurement have proven that the operative temperature in the laboratory in hot, torrid days in many cases is higher than in comfort standards presented for different building functions.

In the future we plan to continue the measurements and to use the calculation method in order to analyse the cooling load and cooling energy in different building comfort category and function.

\section{Acknowledgements}

This paper was supported by the János Bolyai Research Scholarship of the Hungarian Academy of Sciences.

The authors would like to express their gratitude to the Agro-Meteorological Observatory, Debrecen, for providing indispensable meteorological data.

\section{References}

[1] Arif M., Katafygiotou M., Mazroei A., Kaushik A., Elsarrag E. (2016), Impact of indoor environmental quality on occupant well-being and comfort: A review of the literature. International Journal of Sustainable Built Environment, 5(1), 1-11.

[2] Kalmár F. (2016), Interrelation between glazing and summer operative temperature in buildings. Int. Rev. Appl. Sci. Eng., 7(1), 51-60.
[3] Ministry of National Development: National Energy Strategy

[4] European Parliament and its Council 2010/31/EU Directive, 2010.

[5] Official Journal of the European Union L 156/77 (15)

[6] Maragogiannis K., Dionysia K., Efpraxia-Aithra M. (2011), Study of night ventilation efficiency in urban environment: technical and legal aspects. Scientific Journal of Riga Technical University. Environmental and Climate Technologies, 6(1), 49-56.

[7] Omrani S. (2018), Natural ventilation in high-rise apartments in hot-humid climates. Diss. Queensland University of Technology.

[8] https://www.buildinggreen.com/feature/expandingengineers-comfort-zone-working-adaptive-thermalcomfort. (Downloaded: 11.10.2018).

[9] Yang L., Li Y. (2008), Cooling load reduction by using thermal mass and night ventilation. Energy and Buildings, 40(11), 2052-2058.

[10] https://knowledge.autodesk.com/search-result/caas/ simplecontent/content/night-purge-ventilation.html. (Downloaded: 11.11.2018)

[11] Kolokotroni M., Webb B. C., Hayes S. D. (1998), Summer cooling with night ventilation for office buildings in moderate climates. Energy and Buildings, 27(3), 231-237.

[12] Artmann N. (2009), Cooling of the building structure by night-time ventilation. Diss. Department of Civil Engineering, Aalborg University.

[13] https://www.eawag.ch/fileadmin/_processed_/csm_27_ 8c8a406f8jpg (Downloaded: 11.11.2018)

[14] Zhivov A., Skistad H., Mundt E., Posokhin V., Ratcliff M., Shilkrot E., Strongin A. (2001), Principles of air and contaminant movement inside and around buildings. In: Industrial Ventilation Design Guidebook. Academic Press, pp. 415-599.

[15] Csáky I., Kalmár F. (2012), Simulation of the internal temperature in the PASSOL Laboratory, University of Debrecen. Int. Rev. Appl. Sci. Eng., 1(3), 63-73.

[16] Csáky I., Kalmár F. (2015), Effects of thermal mass, ventilation and glazing orientation on indoor air temperature in buildings. Journal of Building Physics, 39(2), 189-204.

[17] Measurement data monitoring with testo Saveris Professional Edition, Instruction manual

[18] Hungarian Meteorological Service, 2015

[19] ISO 7730-2005: Ergonomics of the thermal environment-Analytical determination and interpretation of thermal comfort using calculation of the PMV and PPD indices and local thermal comfort criteria.

[20] EN 15251:2007: Indoor environmental input parameters for design and assessment of energy performance of buildings addressing indoor air quality, thermal environment, lighting and acoustics.

[21] ASHRAE Handbook, Fundamentals, ASHRAE, Atlanta, 1985

[22] EN ISO 13790:2008 (2008) Energy performance of buildings - Calculation of energy use for space heating and cooling. 